bination in which they cannot be recognised by the spectroscope (which is also hardly admissible at that elevated temperature), or that they have been decomposed."

The important work of Victor Meyer on the behaviour of chlorine and iodine at elevated temperatures which must now be regarded as finally established by the experiments of which an account is given in the recent number of the Berichte der deutschen chemischen Gesellschaft (March, I880), and on which 1 ventured to offer some theoretical considerations in a paper which appeared in the F. Chem, Soc. last autumn, point in the same direction. It is difficult not to admit the force of such a body of coincident evidence as that of which I have here given a brief outline.

March 14

B. C. BRODIE

\section{The Aurora at Last}

YESTERDAY, Wednesday, March $\mathbf{I}$ 7, was a magnificently bright sunshiny day from early morning to latest evening; and at 9 p.m. the aurora appeared, just as it used to do years ago in the last sun-spot cycle, and when that strange influence was in its then vigorous existence. Your readers were warned last October that the sun-spots of the new cycle had then begun "in earnest," and now we have to chronicle the first of their auroral fruits.

It was a long low arc of mild quiescent light, about $2^{\circ}$ in transverse breadth, $20^{\circ} \mathrm{long}$, rising about $7^{\circ}$ high in the middle, and sensibly dark between its lower edge and the horizon; the centre was over the north-north-west point of the horizon, but swayed slowly several degrees of azimuth on either side. Towards I I p.m. the arc began to break up into brighter pellets of light, and these shot fainter rays upwards, making a brilliant and variegated appearance for a few minutes, but apparently soon exhausting itself, for after that there remained only a faint ghostly image of the arc up to I a.m.; all this being clearly visible to the naked eye, although a moon seven days old and in $24^{\circ} \mathrm{N}$. Decl. was shining brightly in the west.

In the spectroscope, with a narrow slit, nothing but the one inscrutable citron-coloured line appeared, its place in wavenumbers, per British inch, and as ascertained in both hydrogen and carbonic oxide vacuum tubes, being between 45592 and 45690 .

r5, Royal Terrace, Edinburgh, March 18

\section{A Museum Conference}

ALLOW me to deprecate most strongly any attempt to form an association having for its object to talk about museums. Museum officials either know their business or they do not. In the former case they have something better to do than to talk; in the second case the less they say the better. The multiplication of conferences threatens to become a nuisance, and special conferences for every grade, class, and description of humanity will soon be proposed by fussy idlers. We shall be told that it is time to have a conference of houselkeepers, of lamplighters, of railway guards, boot-makers, beadles, perhaps ballet-girls.

The fact is that endless time and trouble and money are wasted in England in maintaining rubbishing local museums in the care of ignorant and pretentious curators. Conferences are not required, but proper salaries for the curators, who should be educated and capable men; were such men secured by adequate salaries they would soon make the museums in their charge very different from what they now are.

A curator with proper salary ought to be made to attend daily at his museum during office hours, and not allowed to leave it to take care of itself whilst he is lecturing here or there, or eking out his pay by literature.

ACADEMICUS

I $\Lambda M$ glad to see that Mr. Paton has, in Nature, vol, xxi. 1). 442, again revived the subject of a museum conference, and offers to give his aid towards such attaining a practical form. The desirability of a Museum Association was first suggested in an article in NATURE, vol. xv. p. 276, and this was followed by a more definite proposal for a conference by "J. P.," and with the addition of a letter in favour of the same object by Dr. Meyer nothing further was published about it. This looked as if the subject was not considered of any great importance, but I believe many curators were decidedly in favour of it, and only awaited it assuming a practical form to give it their hearty sup port. The success which has attended the Library Association give; every reason to believe that the formation of a similar association of museum officials would lead to equally good results. Apart from the benefits to be derived from an interchange of ideas and results of experience, which, considering the varied nature of museums and the many practical questions involved in their successful management, could not fail to be considerable, there are many things affecting provincial museums generally that would be greatly advanced by united action. One of these, the distribution of the British Museum duplicates, I should like to refer to. In the British Museum Removals Bill a clause was inserted at the instigation of Mr. Mundella, M.P., and Mr. Chamberlain, M.P., which states that "the Trustees of the British Museum may also give away any duplicate works, objects, or specimens not required for the purposes of the Museum." Instead of giving away, however, I learn that the Trustees are about to sell by auction some of the duplicate prints, drawings, \&c., in the Museum; and fearing that other duplicates might be disposed of in a similar manner I had the matter brought before Mr. Mundella, who obtained an interview with the Right Hon. Spencer Walpole, Chairman of the Trustees, and was informed that instructions had been given for duplicates in the Natural History Departments to be laid aside and catalogued for distribution among the principal museums. This is somewhat reassuring, but why not treat all their duplicates in this way?-for it should be remembered that provincial towns contribute their share of imperial taxes.

I must not, however, occupy your valuable space with matters that ought properly to be discussed by such a conference as Mr. Paton suggests; and I hope that all who are interested in museums will heartily co-operate with $\mathrm{Mr}$. Paton, whose great success in developing the museum at Glasgow and his extensive acquaintance with museums both in Britain and on the Continent, eminently qualify him to speak with authority on the subject.

Sheffield Public Museum, March 23 E. HowarTH

\section{A Method of Calculating the Expansion of a Substance on Vaporisation}

HAVING occasion last summer to determine the volume of gas which would result from the vaporisation of a given quantity of a certain solid, I made use of a simple way of obtaining approximate results which may not prove uninteresting to some of your readers, unless, as is very likely, they have already made use of it or a better way themselves. For purposes of illustration we may take it that I gram of hydrogen gas occupies a volume of $\mathrm{II}, 200$ c.c. at normal pressure and temperature; moreover, the weight of $\mathrm{I}$ c.c. of water is $\mathbf{I} \mathrm{gm}$. at $\mathrm{O}^{\circ} \mathrm{C}$.

Knowing the atomic weight and specific gravity of any liquid or solid, we can now find the volume which I c.c. of it will assume on passing into the gaseous state by a simple "rule of three" sum.

For the weight of I c.c. of the substance is given by the number which indicates its specific gravity; and the weight of I I, 200 c.c. of its gas is given by its atomic weight.

Hence

$$
\frac{\text { sp. gr. }}{\text { at. wt. }} \times \mathbf{1} 1,200=\text { vol. },
$$

to which I c.c. of the substance expands on becoming gaseous.

$\mathrm{It}$ is interesting to note that the fraction $\frac{\mathrm{sp} \text {. gr. }}{\mathrm{at} . \mathrm{g}}$ is the recipro.

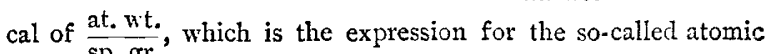
volume $(v)$ of a substance, and thus the expansion of I c.c. of a solid or liquid as it becomes gaseous may also be determined by dividing the number II, 200 by the atomic volume of the substance.

In this way we find that I c.c. of sodium will occupy 474 c.c. in the state of gas, and I c.c. of potassium 249 c.c., or, what is the same thing, I c.c. of each of these substances in the gaseous state will occupy $\frac{1}{4} \frac{1}{4}$ c.c. and $\frac{1}{4} \frac{1}{2}$ c.c. in the solid state respectively. But equal volumes of gas under the same conditions of temperature and pressure contain an equal number of molecules, and hence $\frac{1}{474}$ c.c. and $\frac{1}{24}$ c.c., the products of the condensation of equal volumes of potassium and sodium gas must contain an equal number of molecules. From this we readily deduce

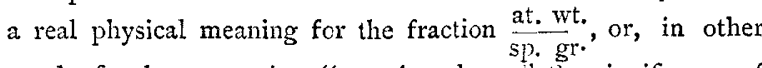
words, for the expression "atomic volume," the significance of which, at first, was merely conjectured.

Lists of homologous series of elements and compounds, with their " "condensation numbers" attached, give very interesting results; I have only one such at hand, which I here give:- 